\title{
A concept-environment for computer-based augmentative and alternative communication founded on a systematic review
}

\author{
Luiz Fernando Batista Loja*, Renato de Sousa Gomide, Fabiana Freitas Mendes, \\ Ricardo Antonio Gonçalves Teixeira, Rodrigo Pinto Lemos, Edna Lúcia Flôres
}

\begin{abstract}
Introduction: Locked-In Syndrome is admittedly the worst case of motor and speech impairment, it seriously damages the ability of oral and gestural communication of patients. In recent years, alternative and augmentative communication technology has provided resources to restore these patients' ability to communicate. Methods: In order to relate and classify the main methods with that purpose, this work conducted a systematic review on several journal databases. Results: We found 203 related papers and 55 of them were selected to compose the study. After that, we classified them into three major groups and we identified the main difficulties when using each approach. Conclusion: In order to overcome these difficulties, we propose a new system concept to develop an adaptive, robust and low cost communication environment. The proposed system is composed of five modules: data entry, communication, aid to the caregiver and external interaction.
\end{abstract}

Keywords: Computer, Augmentative and alternative communication, Systematic review, Locked-in syndrome, Assistive technology.

\section{Introduction}

The contemporary society has been developing technologies to support people with physical or mental disabilities. These limitations usually deprive people from social contact and from accessing to cultural goods. In extreme cases, they even become unable to interact with others or with the environment (Caltenco et al., 2012).

Currently, we can find techniques, methods and devices designed to improve the conditions of communication, mobility, accessibility, development of skills and competences of those people. Over the last decades, the inclusion of disabled people has become a cause championed by organized social movements. They aim to develop concrete conditions of social integration of people with visual, physical, hearing and intellectual impairments or multiple disabilities (García and Galvão, 2012).

This scenario has motivated scientific researchers to better understand the needs of impaired people and to develop practical devices, techniques and methods to minimize their limitations.

This technological apparatus belongs to the interdisciplinary area of knowledge known as Assistive Technology (AT), which encompasses products, resources, methodologies, strategies, practices and services. They provide functionalities related to the activities of disabled people, impairments or reduced mobility, in order to improve their autonomy, independence, quality of life and social inclusion (Brasil, 2004).

The development of AT counts on the contributions of multiple areas of expertise, like medicine, engineering, computer science, physical and occupational therapy. Specially, Computing has great potential to contribute to advancing AT through integrating information processing and communication tools in a multimedia context.

Park et al. (2012) concluded that, due to the increasing popularization of computers and the internet expansion, many studies have been carried out to assist the communication of people with aphasia and tetraplegia. Augmentative and Alternative Communication (AAC) is an important field of AT that comprises the methods and technologies designed to assist or replace the oral communication of people with limited speech (Wilkinson and Hennig, 2007).

Locked-In Syndrome (LIS) is admittedly the worst case of motor and speech impairment, seriously damaging the ability of oral and gestural communication of patients. LIS patients completely lose their motor functions of upper and lower limbs, keeping only limited motor stimuli such as eye movements (Keegan et al., 2009). This syndrome can be caused by: Cerebral Palsy, Amyotrophic Lateral Sclerosis 
(ALS), Tetraplegia and degenerative diseases of the nervous system (Cardwell, 2013).

According to Mak and Wolpaw (2009) and Sorger et al. (2009), there are three types of LIS: incomplete, classic and complete. In Incomplete LIS, the individual shows limited voluntary movements, such as moving a finger or part of the face. People who suffer from Classic LIS can only move or blink their eyes. Finally, in Complete LIS, the patient is unable to perform voluntary movements anywhere in the body.

Patients with LIS are unable to perform oral or gestural communication. They require devices that provide alternative ways to express themselves. Two types of biologic signals can be converted into computer commands to promote communication: the eye movements and the brain activity (Cipresso et al., 2011).

AAC can be used as a mean of coding and transmission of messages by transforming these biological signals into computer decodable information. For instance, the eye movements can be acquired by video cameras (Park et al., 2012) or by recording signals from the eye muscles (Electrooculography EOG) (Usakli et al., 2009). The most used technique to acquire brain activity is the Electroencephalography (EEG) (Cabrera et al., 2008).

These computational communication systems have two essential elements: the input device and the communication software. The input device is used to capture any type of voluntary intent of the patient. The eye movements were used as inputs in Park et al. (2012) and Cipresso et al. (2011), while Blain et al. (2008), Schalk et al. (2008), Usakli et al. (2009) and Al-Abdullatif et al. (2013) used patient's brain activity to provide communication resources.

The communication software is a program specially developed to analyze the data captured by input devices and turns them into information. There are many types of programs ranging from virtual keyboards (Doval et al., 2010; Fu and Ho, 2009; Orhan et al., 2012) to complex communication spreadsheets (Biswas and Samanta, 2008; Mason and Chinn, 2010).

The main goal of this systematic review is to identify publications in computer science that have researched or developed artifacts and tools to support people with classic LIS. Among them, we are especially interested in those AAC methods, techniques and devices that have shown to be less invasive and more adaptable. Then, we intend to find their limitations and propose an integrated communication environment that overcomes the main issues that we have identified.

This paper is structured as follows: Section Planning describes the planning of this review, the parameters adopted in the search engines and the criteria of selection. The systematic review and a preliminary selection are presented in Section Protocol Implementation. Section Data Analysis shows the final selection and also analyses those selected works. Then, a new AAC environment is derived from this analysis in Section Proposition of an Alternative and Augmentative Communication Environment. Finally, Section Conclusion brings the concluding remarks and suggestions for future works.

\section{Planning}

This Systematic Review (SR) was planned according to the protocol presented by Biolchini et al. (2007). The main aspects are presented in this section.

\section{Research objectives}

The aim of this work is to identify and analyze the techniques, methods and computational devices used to support the communication of people with classic LIS. Specifically we intend to: (1) find the less invasive techniques, methods, devices and software with greater adaptability; (2) identify the limitations associated to using those methods, devices and software; and (3) propose an integrated communication environment that overcomes the main issues we have identified.

\section{Formulation and research question: scope and specificities}

The main goal of the research questions is to identify the works that belong to the areas of Computing and Augmentative and Alternative Communication: (1) which AAC techniques and methodologies use computing devices to assist people with classic LIS? and (2) among them, which technologies are less invasive?

The first question was used to find the computational devices, which is the general objective of this work. The second examines whether the solutions are less invasive. The specificities of this study are described below:

1. Intervention: Techniques and methodologies that use computational devices.

2. Control: This research initially began with the work of García and Galvão (2012) and the articles of Chun (2009), Pinheiro et al. (2011) and Arnott and Alm (2013).

3. Population: Augmentative and alternative communication techniques and methodologies that use computational devices to assist people with classic LIS. 
4. Results: The state of art of Assistive Technologies for Augmentative and Alternative Communication that use computational devices to support people with classic LIS. In addition, we have identified whether these technologies have been implemented or simply modeled.

5. Application: This work will indicate theoretical and practical resources for nurses, physicians, occupational and physical therapists and even family members to interact with people with classic LIS. Also, it will help computer professionals expand their knowledge on AT. Besides, this review will allow designing a communication environment to minimize the limitations on using current AAC systems.

\section{Search strategy for selecting studies}

Initially, we defined the selection criteria and which searching methods (manual, electronic search engines, etc.) would be considered. Then, we chose the languages for which the search would be restricted. Finally, we set the keywords and search strings. The keywords were defined according to the objectives and issues presented in this work. The search string to be used in the search engines was initially built in Portuguese and then translated into English. This method and all its features are described below.

1. Criteria for sources selection: only indexed databases and internet-based electronic search engines were selected.

2. Search methods of sources: in databases and search engines, we used filters for date and combined keywords in strings by using logical operators AND and OR. The engines searched in title and abstract of the papers.

3. Keywords: we used "additional communication", "alternative communication", "augmentative communication", "augmentative and alternative communication".

4. Sources: according to Kitchenham and Brereton (2013), we had better seek in specific search databases and use at least one general search engine. Then, we used the Periodicos CAPES Portal and the Scirus database aggregator as general bases. As the specific database, we chose IEEEXplore digital library.

5. Types studies: they were performed on journal and conferences papers, patents, reviews, theses and dissertations.

6. Language of the studies: we used English and Portuguese. English has been chosen due to his international acceptance for publishing scientific papers. Portuguese has been considered to ensure the inclusion of relevant works from Brazilian researchers.

\section{Criteria and procedures for selecting studies}

Aiming at the most relevant works, we refined the search by applying inclusion and exclusion criteria to the title and abstract of each selected document. These criteria were suited to the search strategies lately described in this work. Then, we removed both the irrelevant papers and those with incomplete electronic version. These criteria are described below.

\section{Inclusion criteria}

The purpose of the inclusion criteria is to qualify the relevance of each work according to this systematic review.

1. Inclusion Criterion 1 (IC1): papers must be digitally available for free on the internet or through agreements.

2. Inclusion Criterion 2 (IC2): only full papers written in English or Portuguese must be considered.

3. Inclusion Criterion 3 (IC3): papers must use computational devices as an AAC interface.

\section{Exclusion criteria}

The aim of the exclusion criteria is discard papers that do not fit on this systematic review.

1. Exclusion Criterion 1 (EC1): papers depend on a physical device that is not adaptable to the computational environment.

2. Exclusion Criterion 2 (EC2): papers rely on devices that demand interaction through speech or movements of upper and lower limbs.

\section{Search string}

Focusing on Research Question 1, we tried to find out papers on "Locked-In Syndrome". However, due to its interdisciplinary nature, the search did not yield good results. In order to broaden the search on AAC technologies we modified the search string to include AAC synonyms (Chun, 2009), and we validated the results with the items of control (Pinheiro et al., 2011; Arnott and Alm, 2013). Table 1 shows the original search string and its syntax for each search engine. 
Table 1. Original search string and the versions used in search engines.

\begin{tabular}{ll}
\hline \multicolumn{1}{c}{ Version } & \multicolumn{1}{c}{ Search string } \\
\hline Original search String & $\begin{array}{l}\text { Comunicação suplementar OU "comunicação alternativa" OU "comunicação aumentativa" OU } \\
\text { "comunicação alternativa e aumentativa" } \\
\text { IEEEXplore }\end{array}$ \\
$\begin{array}{l}\text { Suplementar communication" OR "alternative communication" OR "augmentative communication" } \\
\text { OR "augmentative and alternative communication" } \\
\text { suplementar communication OR "alternative communication" OR "augmentative communication" } \\
\text { OR "augmentative and alternative communication" }\end{array}$ \\
$\begin{array}{l}\text { Periodicos CAPES } \\
\text { portal }\end{array}$ & $\begin{array}{l}\text { comunicação suplementar OR "comunicação alternativa" OR "comunicação aumentativa" OR } \\
\text { "comunicação alternativa e aumentativa" }\end{array}$ \\
\hline
\end{tabular}

\section{Selection process of studies}

The search string was used for searching on indexed sources in the preliminary selection of the studies. After the selection process, the works were catalogued to ensure that each document was selected only once. Thus, the documents were distributed to two researchers who read their abstracts and conclusions.

Each researcher used the inclusion and exclusion criteria outlined in Section Criteria and Procedures for Selecting Studies to decide whether the work was appropriate or not for this Systematic Review (SR). In case of disagreement, the different opinions were discussed until a consensus was achieved.

After evaluating all works, each researcher recorded his/her reasons of including or excluding each work. In the final selection, those documents included in the preliminary phase were integrally read and evaluated according to the two questions stated in Section Formulation and Research Question: Scope and Specificities. Finally, this evaluation determined whether or not the work would be included in this SR.

\section{Protocol implementation}

The searching used the search engines and digital libraries accessible through Periodicos CAPES portal. Initially, we searched the IEEEXplore database. Then, we used the search string first in Periodicos CAPES portal and next in the Scirus aggregator.

We retrieved 203 papers: 68 on IEEExplore; 1 on Periodicos CAPES portal and 134 on Scirus. The reference manager JabRef 2.9.2/2013 was used to organize the documents retrieved.

Eleven out of the 203 papers were duplicated among the bases. After removing the duplicates, 192 papers remained in the study. Reading their titles and abstracts allowed us to eliminate irrelevant references such that only 55 papers remained to be read in full. Figure 1 illustrates the steps performed in implementing the search protocol.

After we had read the documents in full, three studies written in other languages than English and

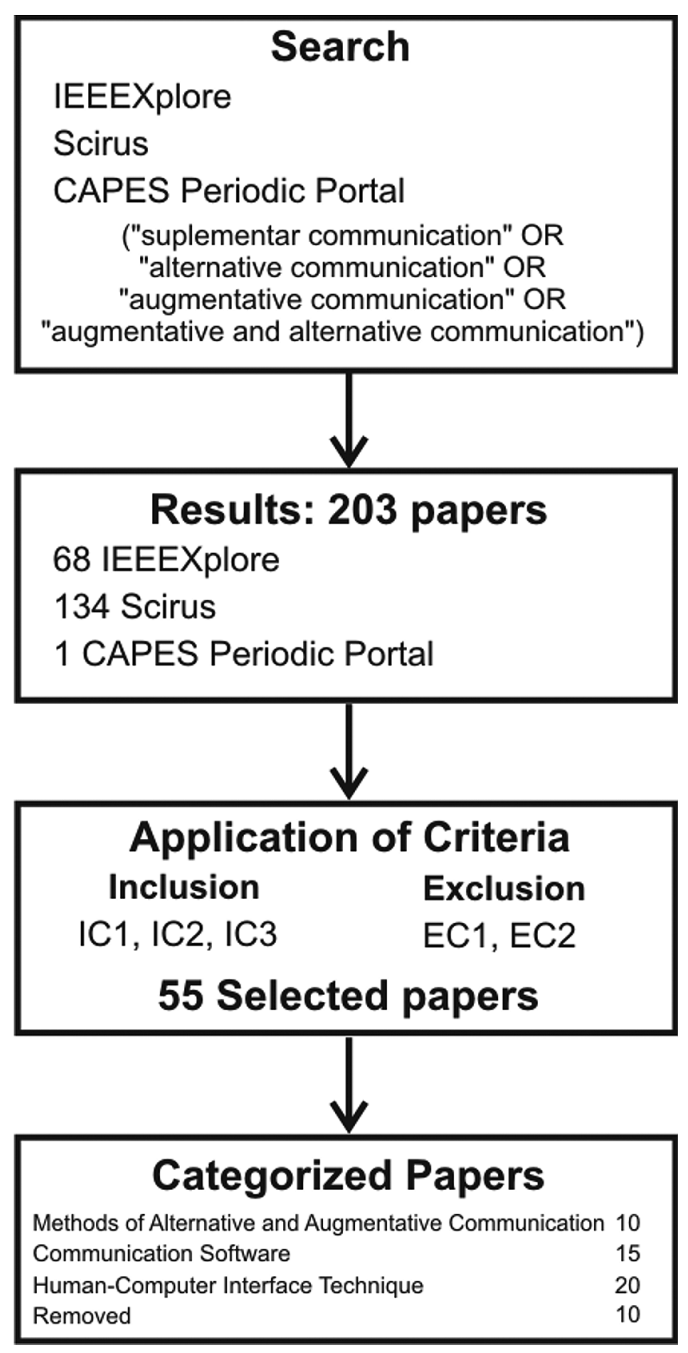

Figure 1. Steps performed in implementing the search protocol.

Portuguese were removed. Additionally, other seven studies were removed because their techniques, software components or methods were not suitable for people with LIS (Exclusion Criteria 2).

According to the main theme of each remaining paper, they were classified into three categories: 
Concepts and Reviews of Augmentative and Alternative Communication (CRAAC); Communication Software (CS); and methods of Human-Computer Interface (HCI). CRAAC includes systematic and literature reviews as well as discussions about AAC. The category Communication Software comprises both modeled and implemented software solutions for improving the communications of people with LIS. Finally, those studies describing any kind of interface between computers and people with LIS were classified as Human-Computer Interface.

Out of 55 fully read papers, we classified 10 as CRAAC, 15 as CS and 20 as HCI. The remaining 10 papers were removed from this study for not fitting any of these categories. Due to the specificities of each paper, we divided each category into subcategories as shown in Table 2.

\section{Data analysis}

The main goal of this section is to summarize the information collected from the selected papers. Table 3 relates those papers to the subcategories early presented in Table 2 .

In order to identify contributions of each work to alternative and augmentative communication environments, the papers were analyzed according to the components proposed by Hill (2010), who divides these environments into three components: primary, secondary and tertiary.

The primary components indicate the way the communication environments represent natural language: single meaning images, alphabet-based techniques or semantic compaction. These concepts are technology independent (Hill, 2010) and are used to define the communication strategies of AAC devices.

Table 2. Papers classified in categories and subcategories.

\begin{tabular}{|c|c|c|}
\hline Category & Subcategory & $\begin{array}{c}\text { Number of } \\
\text { papers }\end{array}$ \\
\hline \multirow[t]{3}{*}{ Concepts and reviews of augmentative and alternative communication } & Systematic review & 2 \\
\hline & Exploratory study & 1 \\
\hline & Conceptual review & 7 \\
\hline \multirow[t]{3}{*}{ Communication software } & Alternative virtual keyboard & 3 \\
\hline & Communication board & 6 \\
\hline & Modeling software & 6 \\
\hline \multirow[t]{5}{*}{ Human-computer interface } & Facial expression & 1 \\
\hline & Brain-computer interface & 15 \\
\hline & Eye tracking & 2 \\
\hline & Speech recognition & 1 \\
\hline & Electrooculogram & 1 \\
\hline Removed & & 10 \\
\hline Total & & 55 \\
\hline
\end{tabular}

Table 3. Papers selected and classified for systematic review.

\begin{tabular}{|c|c|}
\hline Paper & Category \\
\hline $\begin{array}{l}\text { (Bermúdez et al., 2010), (Cabrera et al., 2008), (Chin et al., 2010), (Deepa et al., 2010), (Okasaka } \\
\text { and Hoshino, 2012), (Schalk et al., 2008), (Sorger et al., 2009), (Sun et al., 2010), (Thomas et al., } \\
\text { 2008), (Thompson et al., 2013), (Ortner et al., 2011), (Al-Abdullatif et al., 2013), (Besio et al., } \\
\text { 2009), (Usakli et al., 2009), (Ming et al., 2009) }\end{array}$ & $\mathrm{BCI}$ \\
\hline (Hanson et al., 2010) & $\begin{array}{l}\text { Speech generator } \\
\text { device }\end{array}$ \\
\hline (Keegan et al., 2009) & $\mathrm{EOG}$ \\
\hline (Joubert et al., 2011) & Exploratory study \\
\hline (Ann and Theng, 2011b) & Facial expression \\
\hline (Park et al., 2012), (Cipresso et al., 2011) & Eyetracking \\
\hline $\begin{array}{l}\text { (AlJa'am et al., 2008), (Ann and Theng, 2011b), (Friginal et al., 2013), (Car et al., 2011), } \\
\text { (Sorna et al., 2009), (Hsieh et al., 2009) }\end{array}$ & Software modeling \\
\hline $\begin{array}{l}\text { (Arboleda et al., 2009), (Biswas and Samanta, 2008), (Bhattacharya et al., 2008a; 2008b), (Silva and } \\
\text { Pereira, 2011), (Tsai, 2013) }\end{array}$ & $\begin{array}{l}\text { Communication } \\
\text { board }\end{array}$ \\
\hline $\begin{array}{l}\text { (Belani, 2012), (Arnott and Alm, 2013), (Deepa et al., 2010), (Hill, 2010), (McCoy et al., 2013), } \\
\text { (Mak and Wolpaw, 2009), (Pinheiro et al., 2011) }\end{array}$ & Conceptual review \\
\hline (Alwell and Cobb, 2009), (Finke et al., 2008) & Systematic review \\
\hline (Doval et al., 2010), (Prabhu and Prasad, 2011), (Orhan et al., 2012) & $\begin{array}{l}\text { Alternative virtual } \\
\text { keyboard }\end{array}$ \\
\hline
\end{tabular}


The user interface, the selection and control methods and the software output are part of the secondary components. These components depend on the technology used in developing the CS environment.

The user interface comprises spreadsheet communication, virtual keyboards, text prediction methods and speech processors. Data entry is performed by methods of control and selection like Brain-Computer Interface (BCI), eye tracking and eye stimuli (Hill, 2010). Speech synthesizing, text messaging, sending messages to mobile devices and any interaction with other electronic devices are used as outputs of the communication system.

The tertiary components concern to the adequacy of the communication system to the user's satisfaction. The main reasons that lead users to abandon AAC systems are inadequate support and training, difficult maintenance and adjustment in software (Johnson et al., 2006; Kraskowsky and Finlayson, 2001).

In the next subsections we will discuss each paper of this systematic review regarded to this three categories.

\section{Primary components}

Arboleda et al. (2009) used an array of four rows by three columns where the user can write a message or select daily activities like, for instance, ask for water or say if he is feeling good or bad. The system automatically displays images and letters and the patient sends a signal selecting the desired option. In Usakli et al. (2009), the authors adopted a hybrid strategy using both images and characters to replace natural language. In their worksheet, the user can express his will by choosing among several pictures, write texts by using a virtual keyboard or control the mouse by using arrows that represent the motion direction.

The works of Orhan et al., (2012) and Prabhu and Prasad (2011) used alphabets to represent natural language. Orhan et al. (2012) used a simple interface that sequentially displays the letters of the alphabet, one by one, until the user identifies the intended letter and choose it. Then the system inserts the letter in the text. Prabhu and Prasad (2011) developed a circular keypad with a word prediction modulus. In this keypad, the letters are grouped into sectors such that when a sector is selected, the respective letters are automatically displayed. As the user starts selecting the initial letters of a word, the prediction modulus automatically suggests a list of words to be chosen. On the other hand, Doval et al. (2010) developed a virtual keyboard without function keys. They grouped consonants, vowels, numbers and punctuation in specific keys that are discriminated by using different colors.

Silva and Pereira (2011) represented natural language by semantic compaction. The system displays a matrix of symbols and their descriptions. The user may compose statements by concatenating a sequence of images selected from this matrix. Although effective to convey simple messages, this method does not allow the user to express formal or detailed information.

\section{Secondary components}

The external human-computer interface is defined by the stimuli the patient can do. The survey reported the recognition of degraded speech, facial expressions, eye movements and $\mathrm{BCI}$ as communication interfaces.

In case of patients whose speech is mostly preserved, word prediction systems and voice processors can be used to improve speech quality. Hanson et al. (2010) presented a prototype of a communication device that first recognizes degraded speech and then outputs the correspondent sentence through synthesized speech.

Ann and Theng (2011a) developed a system for people with cerebral palsy where the messages can only be chosen from a predefined database. The user interaction is provided by the recognition of facial expressions acquired by a simple webcam.

In case of LIS patients, as both their speech and facial muscle movements are restricted (Sorger et al., 2009), eye movements must be used as stimuli in the human-computer interface. These movements can be tracked by using image processing (Park et al., 2012) or even by measuring the activity of the eye muscles (Keegan et al., 2009). BCI is recommended only for people with full LIS. BCI systems monitor brain activity features and encode them as control signals for various devices (Schalk et al., 2008). BCI operation comprises the following activities: signal acquisition, feature extraction, feature coding, device output, and operation protocol (Mak and Wolpaw, 2009).

Brain activity can be monitored by electrophysiological or hemodynamic signals (Sorger et al., 2009). The signal nature is the main factor for choosing the most suitable BCI techniques. However, this choice also depends on financial factors, physical space, mobility device, response time, accuracy, adequacy to the user, and installation complexity (Mak and Wolpaw, 2009). BCI was adopted in some works (Besio et al., 2009; Chin et al., 2010; Deepa et al., 2010; Okasaka and Hoshino, 2012; Schalk et al., 2008; Sun et al., 2010; Thomas et al., 2008) and also in AAC complete systems (Arboleda et al., 2009; Prabhu and Prasad, 2011). More than one technique can be used to provide Human-Computer Interfacing. In Usakli et al. (2009) 
and Cipresso et al. (2011) eye movements and BCI were used together.

\section{Tertiary components}

Hill (2010) divides the tertiary components in three elements: peripheral and integrated features, training and support, and telerehabilitation. Peripheral and integrated features are related to how easy is to mount, position and transport an AAC device. Training and support features include customizations on the AAC equipment and periodic maintenance. Finally, telerehabilitation consists in providing remote rehabilitation services using electronic communication and information technologies.

Kübler et al. (2006) state that peripheral and integrated features require efforts in installation, calibration and operation. Additionally, according to Simpson (2008), high costs of maintenance and technical support can discourage the continued use of this technology.

The complexity of the interface can lead the user to frustration in face of difficulties to adapt to the technology (McCoy et al., 2013). Training and support features can minimize this problem implementing a customization interface (Biswas and Samanta, 2008).

The user must always be aware of what the AAC systems can offer him and get proficient in the systems that he is using. So, a good telerehabilitation service can also provide training and support for AAC users (Hill, 2010).

\section{Results}

In this section we present a critical view about the papers related in this systematic review, and we answer the research questions proposed in the Planning section.

\section{A critical view}

The structure of this section does not present the research papers in a chronological order. These papers are classified in different area of knowledge due to the interdisciplinary nature of AAC. Therefore, the works are described and grouped according to the similarity among their research problems. This approach aims to set up a link between the papers, our critical point of view and the technological context.

Simpson (2008) analyses that the decision process of acquiring Assistive Technology devices should obey an interactive cycle that comprises data collecting, decision making and product evaluation. This cycle demands reference product analysis, product evaluation both in clinical and domestic environments, product installation and delivering, and user interaction with related tools.

The decision process of choosing an AT product includes collecting information, identifying market available alternatives and fitting to budget requirements. Although Simpson (2008) defines a set of tasks to select an AT system, he does not specify what are the types of data entry interfaces and how to choose one among them.

Additionally to Simpson (2008), Pinheiro et al. (2011) presents a review of Alternative and Augmentative Communication Systems that uses electrical biosignals to build an interface between computers and disabled people. Each method is linked to the limitations of each patient. Pinheiro et al. (2011) also state that there are few business solutions that use electrical biosignal and highlight the difficulties to configure this kind of solution. Therefore, the low number of available options and the additional cost of support, installation, configuration and training, increase the final price of the solution.

Another important issue mentioned by Simpson (2008) is the availability of supplier support. According to Hill (2010) and McCoy et al. (2013), the main issues for interrupting the use of AT solutions are lack of support and training, as well as weak system maintenance. Pinheiro et al. (2011) et al. also highlights that the AT system usage complexity is a critical factor to keep the use of that solution.

However, weak system maintenance is the main reason that patients give up on using AT solutions. This is due to the solution complexity can increase according to the product evolution, and the users must be assisted to adapt themselves to the new features. Unfortunately, AT suppliers sometimes do not offer a good assistance service. A good strategy would be to build this kind of software as an open source development model.

The use of an open source technologies architecture allows the community to support and maintain the AT systems. This kind of support strategy may favor the implementation of improvements on the AT programs. Lakhani and Hippel (2003) report that open-source project can lead to developing good quality products. Furthermore, the evolution and improvement of those solutions run on a collaborative way. Another advantage is that open-source solutions do not have additional support cost, because volunteers typically assume this task on virtual communities. These communities may assist patients to understand and use the new software's features.

The communication rate in AAC systems is quite low. While in a normal conversation, someone speaks over 150 to 200 words per minute, AAC users are able 
to produce less than 15 words per minute (Arnott and Alm, 2013). This low typing performance is related to the input device and the communication software.

The input mechanism of AAC devices directly influences on all system performance. All biological signals must be digitized and interpreted by a computer. There are basically two approaches for digital signal interpretation: detection or classification.

In detection approach, a binary mechanism represents the input data using two states: active or inactive. For instance, in EOG, the signal is considered active in case the user eyes are closed, and inactive when they are open. This approach has some advantages, like its robustness, because the biological signals are very specific and easy to detect. However, this kind of stimulus allows only a single command.

Bhattacharya et al. (2008a; 2008b) used switches activated by hands or mouth, and Schalk et al. (2008) used BCI techniques to create computational commands based on detection mechanisms. The interface employs a scanning mechanism to highlight each option on a screen in a way that a simple a stimulus from the user selects such option. However, the most frequent user error in this kind of interface comes from failing to access the desired option at the right time (Bhattacharya et al., 2008a). This kind of error leads the user to select the wrong option. Bhattacharya and colleagues tried to reduce these interaction errors by employing prediction techniques on virtual keyboards.

On the other hand Schalk et al. (2008) proposed a new BCI technique to translate a brain signal into computer commands. The major impediments in using the BCI technology into clinical applications is the current requirement for preliminary analyses to identify the brain signal features best suited for communication (Schalk et al., 2008). To overcome this problem, Schalk and colleagues collected data from the users when they were in a rest state. The presented approach detects any change that occurs in an appropriate set of this brain signal features. These changes are decoded as an input and converted in a computer command.

The classification approach can generate more than one command for a single input signal. For example, in $\mathrm{BCI}$ the brain signals can be encoded in many different mental images. Then, a computer classifies those images as a pattern and, for each one, a distinct computational command may be generated (Bermúdez et al., 2010). Furthermore, this method can be used in BCI data input, facial expression recognition and combination of eye movement patterns. Nevertheless, this approach sometimes fails to interpret the signal during the classification process. Also, system training and calibration processes are more delicate and require multiple epochs (Ortner et al., 2011).
Ann and Theng (2011b), Keegan et al. (2009), Ming et al. (2009) and Sun et al. (2010) employed the classification approach of biological signal like $\mathrm{BCI}$, facial expressions and saccades sequence. Using facial expressions as input data type, Ann and Theng (2011b) got promising results like low false positive classification results $(8,71 \%)$ and a significant recognition rate $(79,41 \%)$.

In order increase the number of patients able to use the system, Usakli et al. (2009) and Cipresso et al. (2011) proposed a hybrid input interface. Both of them used BCI technology, however, while Usakli et al. (2009) applied EOG to get the ocular signals, Cipresso et al. (2011) captured the eye movement using a camera. Hybrid systems give to the patients the flexibility to choose which device best fits theirs limitations.

Keegan et al. (2009) worked with saccades sequence for command creation. Their method reached $93.75 \%$ of recognition rate, nonetheless this approach demands a huge effort from the user. This effort leads to fatigue after a short period of use (Bahill and Stark, 1975). The input data type can be modified in order to require less effort from the user. Park et al. (2012) used blinking identification as an alternative to data input acquired by camera. Park and his team developed software and devices that allowed a patient to communicate. Despite of the success of this project reported by Park and colleagues, no data related to the performance of these components were presented.

Sun et al. (2010) and Ming et al. (2009) used brain activity signal to generate commands. Sun et al. (2010) used only two possible classifications to the input signal. The authors did not report any results about the accuracy of their approach. Nonetheless, they suggested improving the classification of many patterns to a single input signal. On the other hand, Ming et al. (2009) improved the work of Sun et al. (2010) to allow interpreting the stimulus into many specific classes. This method got a significant classification rate of $80 \%$.

Once more, the best data entry approach depends on the patient's limitations. Naturally, pattern recognition seems to be a good choice because it provides a larger number of direct commands making the HCI more efficient. Nevertheless, a large number of distinct commands demand a larger amount of classes. The process of decoding a large amount of classes is laborious, impractical and demands a good storage space (Schalk et al., 2008). Besides, lot of classes may cause identification errors, and a higher error recognition rate may lead the patient to feel frustrated and to give up of using the system.

The detection approach, however, demands smaller operational and learning efforts from the user. Besides 
this method requiring less computational effort for command codification, it also shows less interpretation errors. After a benchmarking, they concluded that the pattern recognition approach must be applied first and, if the user shows any difficult to adapt, the detection approach can be employed.

Furthermore, the user interface must help on performance and learning of the solution. Among the selected works in this review, only Biswas and Samanta (2008) focused on interface improvement and presented an AAC system they called "Friend".

This system uses figures and alphabets to construct messages and allows the dynamic customization of the interface according to its utilization. Although the system robustness, its graphical interface is confusing because it simultaneously displays a great amount of information for the user on a single screen.

To avoid visually polluting the interface, a preliminary study must be made in order to discover the main user needs as the interface shows only those options with higher priority. Another approach could be organizing the options on a menu structure according to the user needs.

An AAC solution can build messages by employing three kinds of language: text, figures, semantic compaction or a mixture of all these elements. Most of the solutions simply display predefined messages according to the patient's most frequent daily needs. However, this approach is rather limited. In order to improve the usability, the complexity of composing a new message must be minimized through the optimization of the text entry techniques.

Prabhu and Prasad (2011), Doval et al. (2010) Bhattacharya et al. (2008a; 2008b) Orhan et al. (2012), Park et al. (2012) and Naves et al. (2012) presented AAC systems that use only textual language to compose a message, while Silva and Pereira (2011) proposed a system that composes hybrid messages using semantic compaction.

The use of hybrid language, e.g., textual and figure elements, helps the user to easily identify the desired option through the visual identity of each figure such that even illiterate users can use this kind of system. In this case, each figure must have a single meaning and similar images must be avoided on the symbols set of the AAC solution. Furthermore, the amount of figures on the screen demands special attention to avoid producing a confusing graphical interface.

The cultural level and school degree of people who will use the AAC system should take into account in order to define the system language. The textual language is useful only for literate users, while the language that uses symbols and figures may be applied for all kinds of users, literate and illiterate.
One of the most primitive mechanisms for alternatively entering text is the keyboard (Ghosh et al., 2011). However, due to the users impairments, AAC systems employ virtual keyboards instead of physical ones. According to Molina et al. (2009), a virtual keyboard is a kind of software that shows a keyboard layout on the computer screen. This method enables a detailed formal communication and is an essential element for any AAC system when the patient is literate. On the other hand, Kim et al. (2014), Kwon et al. (2009) and Arif and Stuerzlinger (2013) stated that virtual keyboards show lower typing performance than their physical counterparts, even when users have no disability.

Usakli et al. (2009), Arboleda et al. (2009), Bhattacharya et al. (2008a; 2008b), Car et al. (2011) and Orhan et al. (2012) proposed solutions for AAC that were already functional, that is, these solutions were ready to be used by disabled people. Nevertheless, none of them proposed improvements on the virtual keyboard, despite its importance to the communication interface.

According to Poláček et al. (2012), there is still no definitive solution to the problem of low typing performance of the virtual keyboards. However, for virtual keyboards with general purpose, there are strategies for improving the typing performance that vary from layout optimization (Eggers et al., 2003; Yin and Su, 2011) to the use of text prediction methods (Sörensen, 2007). These improvements could also be applied to the construction of more efficient AAC systems.

Among the works found on this review, only Prabhu and Prasad (2011), Doval et al. (2010) and (Orhan et al., 2012) proposed improvements on virtual keyboards. Prabhu and Prasad (2011) and Doval et al. (2010) works took advantage of the letter frequencies in the English language to build an improved layout and also employed text prediction methods. However, only Prabhu and Prasad (2011) proposed an ambiguous keyboard where each key is associated to more than one letter. This kind of keyboard is more suitable for assistive communications, because it requires smaller typing effort (Bhattacharya and Laha, 2012). On the other hand, ambiguous keyboards demand the use of disambiguation algorithms. Prabhu and Prasad (2011) disambiguated the keyboard using distinction between letters.

Orhan et al. (2012) developed communication software that implements the Rapid Serial Visual Presentation (RSVP) paradigm. Instead of displaying a virtual keyboard on the screen, this software sequentially shows each alphabet letter at a time. The presentation order of the alphabet is based on 
a text prediction algorithm. Although Orhan et al. (2012) and Doval et al. (2010) applied prediction techniques, both of them employed unambiguous approaches, what can reduce typing performance and increase user effort.

Among the assistive keyboards described, the most appropriate approach for people with SE was proposed by Prabhu and Prasad (2011). This is because the ambiguous keyboard decreases the typing effort due to reduction of the number of keys. In addition to the disambiguation algorithm a text prediction method can be applied together. The prediction method may suggest words before the user complete the typing process saving some keystrokes. Finally, the keyboard layout organization approach suggested by Doval et al. (2010) may be improved if applied optimization techniques like metaheuristics as genetic algorithms (Levine and Trepagnier, 1990) and ant colony optimization (Eggers et al., 2003).

We identified some limitations of the present AAC environments and data entry devices used to support patients with LIS. Table 4 summarizes the presented drawbacks explained in this section. This table also includes suggestions to improve each limitation.

Table 4. Limitations and improvements of AAC environments and data entry device.

\begin{tabular}{|c|c|c|}
\hline Related works & Limitation & Improvement proposal \\
\hline $\begin{array}{l}\text { (Simpson, 2008), } \\
\text { (Pinheiro et al., 2011) }\end{array}$ & $\begin{array}{l}\text { High cost of } \\
\text { input data } \\
\text { devices }\end{array}$ & Use an existing low cost device \\
\hline $\begin{array}{l}\text { (McCoy et al., 2013), (Hill, } \\
\text { 2010) }\end{array}$ & $\begin{array}{l}\text { Lack of training } \\
\text { and technical } \\
\text { support from } \\
\text { suppliers }\end{array}$ & Develop open source Solution \\
\hline $\begin{array}{l}\text { (Arnott and Alm, 2013), } \\
\text { (Ann and Theng, 2011b), } \\
\text { (Bhattacharya et al., 2008a; } \\
\text { 2008b), (Ming et al., 2009), } \\
\text { (Keegan et al., 2009), } \\
\text { (Schalk et al., 2008), (Sun et al., } \\
\text { 2010), (Thompson et al., 2013) }\end{array}$ & $\begin{array}{l}\text { Low frequency } \\
\text { of data input }\end{array}$ & $\begin{array}{l}\text { Recognize patterns of signals instead of working with the binary } \\
\text { approach }\end{array}$ \\
\hline $\begin{array}{l}\text { (Biswas and Samanta, 2008), } \\
\text { (Mason and Chinn, 2010) }\end{array}$ & $\begin{array}{l}\text { Complex } \\
\text { communication } \\
\text { environment } \\
\text { Interface }\end{array}$ & Conduct a usability study for this type of application \\
\hline $\begin{array}{l}\text { (Prabhu and Prasad, 2011), } \\
\text { (Doval et al., 2010), } \\
\text { (Silva and Pereira, 2011), } \\
\text { (Bhattacharya et al., } \\
\text { 2008a), (Besio et al., 2009), } \\
\text { (Pinheiro et al., 2011), } \\
\text { (Orhan et al., 2012), (Park et al., } \\
\text { 2012), (Silva and Pereira, 2011), } \\
\text { (Naves et al., 2012) }\end{array}$ & $\begin{array}{l}\text { Homogeneous } \\
\text { strategy } \\
\text { representation } \\
\text { of natural } \\
\text { language }\end{array}$ & Representing natural language by symbols and letters \\
\hline $\begin{array}{l}\text { (Prabhu and Prasad, } \\
\text { 2011), (Usakli et al., } \\
\text { 2009), (Doval et al., } \\
\text { 2010), (Arboleda et al., } \\
\text { 2009), (Besio et al., 2009), } \\
\text { (Bhattacharya et al., 2008a; } \\
\text { 2008b), (Biswas and Samanta, } \\
\text { 2008), (Car et al., 2011), } \\
\text { (Pinheiro et al., 2011), } \\
\text { (Orhan et al., 2012) }\end{array}$ & $\begin{array}{l}\text { Arrangement } \\
\text { of the virtual } \\
\text { keyboard keys }\end{array}$ & Designing a set of keys optimized for text input \\
\hline $\begin{array}{l}\text { (Prabhu and Prasad, } \\
\text { 2011), (Usakli et al., } \\
\text { 2009), (Doval et al., } \\
\text { 2010), (Arboleda et al., } \\
\text { 2009), (Besio et al., 2009), } \\
\text { (Bhattacharya et al., 2008a; } \\
\text { 2008b), (Biswas and Samanta, } \\
\text { 2008), (Car et al., 2011), } \\
\text { (Pinheiro et al., 2011), } \\
\text { (Orhan et al., 2012) }\end{array}$ & $\begin{array}{l}\text { Multiple } \\
\text { interactions } \\
\text { for a single } \\
\text { character } \\
\text { selection }\end{array}$ & $\begin{array}{l}\text { Using predictive text techniques to decrease the interaction with the } \\
\text { input device }\end{array}$ \\
\hline
\end{tabular}




\section{Answers of the research questions}

The first question in this systematic review aims to identify AAC techniques and methodologies that use computing devices to assist people with classic LIS. The second question aims to find out which one of these technologies is less invasive.

The Human Computer Interface techniques identified in this systematic review are: Facial Expression, Brain-Computer Interface, Eye Tracking, Speech Recognition and Electrooculogram, as described in subsection Secondary Components and listed in Table 2.

The input signal for HCI devices using eye movement and facial expressions are typically acquired by cameras or surface electrodes. The use of cameras needs no physical contact with the input device, while signal acquisition by EOG requires surface electrodes.

Devices that use speech recognition require microphones for signal acquisition. However, patients with classic LIS are speechless and unable to express themselves through speech.

Finally BCI-based systems use electrodes to perform signal acquisition. There are two types of electrodes: needle or surface electrodes. Both of them require physical contact between the patient and the acquisition device.

Therefore, we concluded that the cheapest and less invasive HCI technique that one can employ on an AAC system is Eye or Face Tracking using cameras. This approach is less expensive because the majority of the computers include a webcam that can be applied for AAC applications. This approach requires no physical contact between the patient and the electronic device, providing a non-invasive solution. Furthermore, there are free software such as ITU GazeTracker (San Agustin et al., 2010) that implement eye tracking algorithms.

However, some patients have no motor control over the eye or face muscles. Therefore, a BCI approach is the only way to allow these patients to use AAC systems. On the other hand, as we have already stated, this solution requires surface electrodes, installation and calibration support, what makes BCI more expensive than a camera based solution.

In the next section, this paper proposes a conceptual communication environment to overcome the limitations presented in Table 4. Additionally, we suggest a hybrid HCI technique to allow any motor impaired patient to use an AAC system.

\section{Proposition of an Alternative and Augmentative Communication Environment}

Each related work in this review brought one or more contributions to AAC area. Some showed improvements in primary components, other in secondary components and few in tertiary components.

In order to develop an adaptive, robust and low cost communication environment, this paper conceives software with four modules: data entry, communication, aid to the caregiver, and external interaction. This software will consist of primary, secondary and tertiary components in order to accomplish the users' communication needs. Figure 2 illustrates the user interaction with the conceived communication environment and its functionalities.

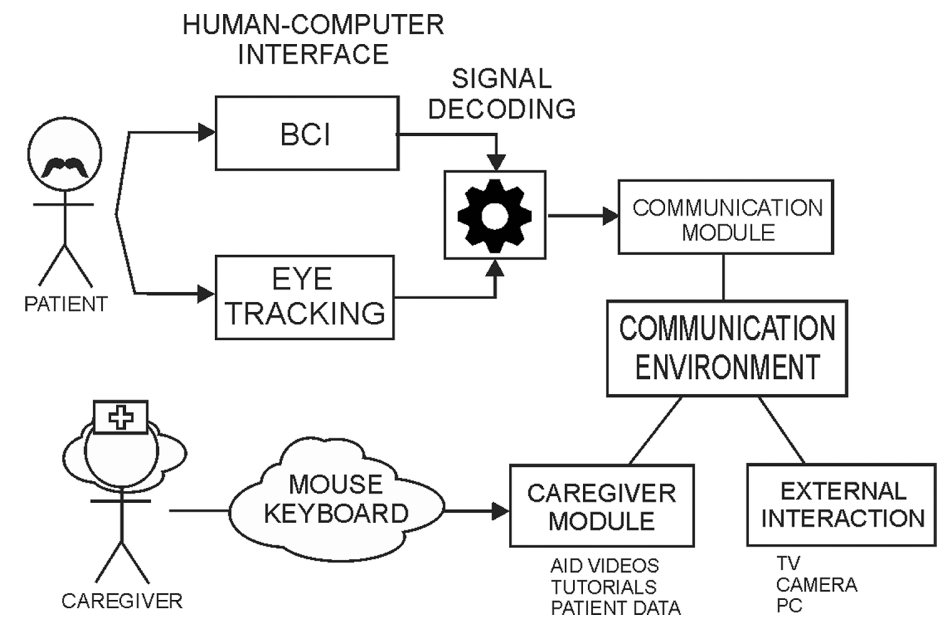

Figure 2. User interaction with the communication environment proposed in this paper. 
Aiming to increase patient's communication speed (Hill, 2010), the communication module shown in Figure 2 will be composed of icons and words that represent the most frequent actions required by the patients. Thus, this module must consist of an optimized, compact, flexible and adaptive hybrid virtual keyboard (alphabet and figures)

In order to minimize the number of interactions required to write a word, text-predicting algorithms will be implemented and used by the virtual keyboard. This keyboard will be compact such that more than one letter is displayed for each key. So, the amount of interactions per key to write a word will be minimized. Finally, the keyboard layout will be adjusted on runtime by changing the order of both the keys and the suggested vocabulary according to their frequency of use.

The use of figures on the communication module will assist the patient to express their basic needs without having to write complete sentences (Tsai, 2013). For instance, if the patient wishes to drink water or take a bath, he will be able to select a figure or even a sequence of figures that represent those actions. The patient will also be able to use both figures and words in the virtual keyboard.

The data entry module will provide a communication interface between the user and the computer. Figure 2 shows the BCI and eye movement techniques that will be used as input data. This interface will be low cost and non invasive.

The aid to the caregiver module will be used to support caregivers in essential procedures to accomplish the will and the daily needs of patients. This module will be able to manage different kinds of media, providing Instructional videos to help supporting the patients in their daily needs like teaching how to position the patient on bed or take him to the bathroom. Also, a system usage manual will be provided in video and text, including technical support information to allow continued use of the communication environment.

The external interaction module will contain input and output interfaces responsible for communication with other software. The aim of this last module is to provide a way of integrating other software in the communication environment, for instance, a kind of software to control a television set.

Whereas most of the works selected in this review usually focused on a single component of the AAC environment, the proposed environment is an integrated system comprising all components. The works of Biswas and Samanta (2008), Doval et al. (2010), Prabhu and Prasad (2011), Naves et al. (2012) and Park et al. (2012) presented a communication system similar to the one here proposed. Although, the software and hardware worked with all components, those systems are not suitable to the Portuguese language and they do not have a compact and optimized virtual keyboard. Furthermore, those studies use a single input device and do not contain modules to aid caregivers and to provide external interaction.

The caregiver module will have informative media and reminders of daily activities. The caregivers will benefit from the use of this environment. Finally, the external interaction module may help the individual with LIS to interact with the external devices.

Among the advantages of the communication environment proposed in this paper, we highlight the use of a hybrid human-computer interface for data entry such that a greater number of people will be able to use it. Another advantage is the compact and optimized keyboard that will use techniques of text predicting, in Portuguese, to make easier the writing of messages easier.

\section{Conclusion}

This systematic review found works on devices, techniques and methodologies to assist directly or indirectly people with Locked-in Syndrome. We selected 45 significant publications. These publications were classified into three categories: Concepts and Reviews of Augmentative and Alternative Communication; Communication Software; and methods of HumanComputer Interface.

Based on the methods of Human-Computer Interface category we identified Eye and Face tracking using cameras as less invasive and cheaper communication technique.

The analysis of the selected works allowed us to list the limitations of using AAC devices when supporting people with LIS. These limitations are mainly related to the delay on the data entry, the adaptability of the human-computer interface to LIS patients.

Besides discouraging the continued use of the AAC communication environments, these limitations result in a fragile process of communication. So, we propose an environment in order to provide more effective communication for people with LIS.

The environment here proposed will comprise modules for data entry, communication, aid to the caregiver, and external interaction. The purpose of the data entry and communication modules is to improve the speed of communication. The aid to the caregiver module aims to provide the caregiver information to help in interacting with patients accordingly to their daily needs. Finally, the external interaction module will integrate the module of data entry with other 
software installed on the same computer in order to allow controlling other devices like a TV set.

The sequence of this work will be made in two stages. The first will be the development of the human-computer interface using $\mathrm{BCI}$ and eye movement tracking. The implementation of the communication software according to the proposal presented in this paper will be the second stage.

\section{References}

Al-Abdullatif A, Al-Negheimish H, Al-Mofeez L, Al-Khalifa N, Al-Andas L, Al-Wabil A. Mind-controlled augmentative and alternative communication for people with severe motor disabilities. In: Proceedings of the 9th International Conference on Innovations in Information Technology (IIT); 2013. 2013. p. 107-12.

Alja'am JM, Alsuwaidi H, Alkuwari N, Aldosari H. Tutorials-based system to assist qatari children with special needs. In: AICCSA 08: Proceedings of the 6th IEEE/ ACS International Conference on Computer Systems and Applications; 2008. p. 945-6.

Alwell M, Cobb B. Social and communicative interventions and transition outcomes for youth with disabilities: A systematic review. Career Development for Exceptional Individuals. 2009; 32(2):94-107. http://dx.doi.org/10.1177/0885728809336657.

Ann OC, Theng LB. A study on the effectiveness of biometrics based alternative communication tool. In: Proceedings of the 8th International Conference on Information, Communications and Signal Processing; 2011. 2011a. p. 1-4.

Ann OC, Theng LB. Biometrics based assistive communication tool for children with special needs. In: Proceedings of the 7th International Conference on Information Technology in Asia; 2011. 2011b. p. 1-6.

Arboleda C, García E, Posada A, Torres R. P300-based brain computer interface experimental setup. In: EMBC 2009: Proceedings of the 31 st Annual International Conference of the IEEE Engineering in Medicine and Biology Society: Engineering the Future of Biomedicine. 2009. p. 598-601.

Arif AS, Stuerzlinger W. Evaluation of a new error prevention technique for mobile touchscreen text entry. In: Proceedings of the 25th Australian Computer-Human Interaction Conference: Augmentation, Application, Innovation, Collaboration [internet]. New York: ACM; 2013. p. 397-400. [cited 2014 May 12]. Available from: http://doi.acm.org/10.1145/2541016.2541063

Arnott JL, Alm N. Towards the improvement of Augmentative and Alternative Communication through the modelling of conversation. Computer Speech \& Language. 2013; 27(6):1194-211. http://dx.doi.org/10.1016/j.csl.2012.10.008.

Bahill AT, Stark L. Overlapping saccades and glissades are produced by fatigue in the saccadic eye movement system. Experimental Neurology. 1975; 48(1):95-106. http://dx.doi. org/10.1016/0014-4886(75)90225-3. PMid:1132472.

Belani $\mathrm{H}$. Towards a usability requirements taxonomy for mobile AAC services. In: UsARE 2012: Proceedings of the 1st International Workshop on Usability and Accessibility Focused Requirements Engineering; 2012. 2012. p. 36-9.

Bermúdez GR, Roca-Gonzalez J, Martínez-González F, PeñaMorán L, Roca-González JL, Roca-Dorda J. Performance analysis of different feature-classifier binomials in MotorImagering BCIs: Preliminary results. In: Proceedings of the 3rd International Symposium on Applied Sciences in Biomedical and Communication Technologies, ISABEL 2010; 2010. 2010.

Besio WG, Kay SM, Liu X. An optimal spatial filtering electrode for brain computer interface. In: EMBC 2009: Proceedings of the 31st Annual International Conference on IEEE Engineering in Medicine and Biology Society: Engineering the Future of Biomedicine. 2009. p. 3138-41.

Bhattacharya S, Laha S. Bengali text input interface design for mobile devices. Universal Access in the Information Society. 2012; 12(4):441-51. http://dx.doi.org/10.1007/ s10209-012-0280-1.

Bhattacharya S, Samanta D, Basu A. Performance models for automatic evaluation of virtual scanning keyboards. IEEE Transactions on Neural Systems and Rehabilitation Engineering. 2008a; 16(5):510-9. http://dx.doi.org/10.1109/ TNSRE.2008.2003377.

Bhattacharya S, Samanta D, Basu A. User errors on scanning keyboards: Empirical study, model and design principles. Interacting with Computers. 2008b; 20(3):406-18. http:// dx.doi.org/10.1016/j.intcom.2008.03.002.

Biolchini JCA, Mian PG, Natali ACC, Conte TU, Travassos GH. Scientific research ontology to support systematic review in software engineering. Advanced Engineering Informatics. 2007; 21(2):133-51. http://dx.doi.org/10.1016/j. aei.2006.11.006

Biswas P, Samanta D. Friend: a communication aid for persons with disabilities. IEEE Transactions on Neural Systems and Rehabilitation Engineering. 2008; 16(2):205-9. http:// dx.doi.org/10.1109/TNSRE.2008.917305. PMid:18403290.

Blain S, Mihailidis A, Chau T. Assessing the potential of electrodermal activity as an alternative access pathway. Medical Engineering \& Physics. 2008; 30(4):498-505. http://dx.doi. org/10.1016/j.medengphy.2007.05.015. PMid:17656143.

Brasil. Decreto No 5.296, de 2 de dezembro de 2004 Regulamenta as Leis nos 10.048 , de 8 de novembro de 2000, que dá prioridade de atendimento às pessoas que especifica, e 10.098, de 19 de dezembro de 2000, que estabelece normas gerais e critérios básicos para a promoção da acessibilidade das pessoas portadoras de deficiência ou com mobilidade reduzida, e dá outras providências. Diário Oficial da República Federativa do Brasil [internet], Brasília, dec. 2004 [cited 2013 Dec 9]. Available from: http://www.planalto.gov.br/ ccivil_03/_ato2004-2006/2004/decreto/d5296.htm

Cabrera AF, Nascimento OFD, Farina D, Dremstrup K. Brain-computer interfacing: how to control computers with thoughts. In: ISABEL 2008: Proceedings of the 1st International Symposium on Applied Sciences in Biomedical and Communication Technologies. 2008.

Caltenco HA, Breidegard B, Jönsson B, Andreasen Struijk LNS. Understanding computer users with tetraplegia: 
Survey of assistive technology users. International Journal of Human-Computer Interaction. 2012; 28(4):258-68. http:// dx.doi.org/10.1080/10447318.2011.586305.

Car Z, Vukovic M, Vucak I, Pibernik J, Dolic J. A platform model for symbol based communication services. In: Proceedings of the 11 th International Conference on Telecommunications. 2011. p. 141-8.

Cardwell MS. Locked-in syndrome. Texas Medicine. 2013; 109(2):e1. PMid:23378122.

Chin S, Lee C, Lee J. Facial expression image mapping for brain-computer interface using El type classification. In: Proceedings of the 3rd International Conference on Information Sciences and Interaction Sciences; 2010. 2010. p. 465-9.

Chun RYS. Comunicação suplementar e/ou alternativa: abrangência e peculiaridades dos termos e conceitos em uso no Brasil. Pró-Fono Revista de Atualização Científica. 2009; 1:69-74.

Cipresso P, Meriggi P, Carelli L, Solca F, Meazzi D, Poletti B, Lule D, Ludolph AC, Riva G, Silani V. The combined use of brain computer interface and eye-tracking technology for cognitive assessment in amyotrophic lateral sclerosis. In: Proceedings of the 5th International Conference on Pervasive Computing Technologies for Healthcare (PervasiveHealth) and Workshops; 2011. 2011. p. 320-4.

Deepa VB, Thangaraj P, Chitra S. Investigating principal component analysis for classification of EEG data. In: ICNIT 2010: Proceedings of the Networking and Information Technology. 2010. p. 461-4.

Doval FMG, Carballo JMP, Vez Jeremías JM. TICTAC: Information and communication technologies for augmentative communication boards. In: Proceedings of the 2010 IEEE Education Engineering Conference. 2010. p. 1783-7.

Eggers J, Feillet D, Kehl S, Wagner MO, Yannou B. Optimization of the keyboard arrangement problem using an ant colony algorithm. European Journal of Operational Research. 2003; 148(3):672-86. http://dx.doi.org/10.1016/ S0377-2217(02)00489-7.

Finke EH, Light J, Kitko L. A systematic review of the effectiveness of nurse communication with patients with complex communication needs with a focus on the use of augmentative and alternative communication. Journal of Clinical Nursing. 2008; 17(16):2102-15. http://dx.doi. org/10.1111/j.1365-2702.2008.02373.x. PMid:18705734.

Friginal E, Pearson P, Di Ferrante L, Pickering L, Bruce C. Linguistic characteristics of AAC discourse in the workplace. Discourse Studies. 2013; 15(3):279-98. http:// dx.doi.org/10.1177/1461445613480586.

Fu YF, Ho CS. A fast text-based communication system for handicapped aphasiacs. In: Proceedings of the 5th International Conference on Intelligent Information Hiding and Multimedia Signal Processing. 2009; 2009. p. 583-94.

García JCD, Galvão TA Fo. Pesquisa nacional de tecnologia assistiva. São Paulo: ITS BRASIL/MCTI-SECIS; 2012.
Ghosh S, Sarcar S, Samantha D. Designing an efficient virtual keyboard for text composition in bengali. New York: ACM; 2011. p. 84-7.

Hanson EK, Beukelman DR, Heidemann JK, Shutts-Johnson E. The impact of alphabet supplementation and word prediction on sentence intelligiblity of electronically distorted speech. Speech Communication. 2010; 52(2):99-105. http://dx.doi. org/10.1016/j.specom.2009.08.004.

Hill K. Advances in augmentative and alternative communication as quality-of-life technology. Physical Medicine and Rehabilitation Clinics of North America. 2010; 21(1):43-58. http://dx.doi.org/10.1016/j.pmr.2009.07.007. PMid:19951777.

Hsieh MC, Hung WS, Lin SW, Luo CH. Designing an assistive dialog agent for a case of spinal cord injury. In: Proceedings of the 9th International Conference on Hybrid Intelligent Systems. 2009. p. 67-72.

Johnson JM, Inglebret E, Jones C, Ray J. Perspectives of speech language pathologists regarding success versus abandonment of AAC. Augmentative and Alternative Communication. 2006; 22(2):85-99. PMID: 17114167.

Joubert K, Bornman J, Alant E. Speech intelligibility and marital communication in amyotrophic lateral sclerosis: an exploratory study. Communication Disorders Quarterly. 2011; 33(1):34-41. http://dx.doi.org/10.1177/1525740110367824.

Keegan J, Burke E, Condron J. An electrooculogram-based Binary Saccade Sequence Classification (BSSC) technique for augmentative communication and control. In: EMBC 2009: Proceedings of the 31 st Annual International Conference of the IEEE Engineering in Medicine and Biology Society: Engineering the Future of Biomedicine. 2009. p. 2604-7.

Kim JH, Aulck L, Bartha MC, Harper CA, Johnson PW. Differences in typing forces, muscle activity, comfort, and typing performance among virtual, notebook, and desktop keyboards. Applied Ergonomics. 2014; 45(6):1406-13. http:// dx.doi.org/10.1016/j.apergo.2014.04.001. PMid:24856862.

Kitchenham B, Brereton P. A systematic review of systematic review process research in software engineering. Information and Software Technology. 2013; 55(12):2049-75. http:// dx.doi.org/10.1016/j.infsof.2013.07.010.

Kraskowsky LH, Finlayson M. Factors affecting older adults' use of adaptive equipment: review of the literature. The American Journal of Occupational Therapy. 2001; 55(3):303-10. http://dx.doi.org/10.5014/ajot.55.3.303. PMid:11723971.

Kübler A, Mushahwar VK, Hochberg LR, Donoghue JP. BCI Meeting 2005-- workshop on clinical issues and applications. IEEE Transactions on Neural Systems and Rehabilitation Engineering. 2006. 14(2): 131-4. PMID: 16792277.

Kwon S, Lee D, Chung MK. Effect of key size and activation area on the performance of a regional error correction method in a touch-screen QWERTY keyboard. International Journal of Industrial Ergonomics. 2009; 39(5):888-93. http://dx.doi. org/10.1016/j.ergon.2009.02.013.

Lakhani KR, Hippel EV. How open source software works: "free" user-to-user assistance. Research Policy. 
2003; 32(6):923-43. http://dx.doi.org/10.1016/S00487333(02)00095-1.

Levine SH, Trepagnier CG. Customised text entry devices for motor-impaired users. Applied Ergonomics. 1990; 21(1):55-62. http://dx.doi.org/10.1016/0003-6870(90)90074-8.

Mak JN, Wolpaw JR. Clinical Applications of Brain-Computer Interfaces: Current State and Future Prospects. IEEE Reviews in Biomedical Engineering. 2009; 2:187-99. http://dx.doi. org/10.1109/RBME.2009.2035356. PMid:20442804.

Mason C, Chinn KM. Augmentative-alternative communication. 3rd ed. Oxford: Elsevier Science; 2010. International Encyclopedia of Education.

McCoy KF, Arnott JL, Ferres L, Fried-Oken M, Roark B. Speech and language processing as assistive technologies. Computer Speech \& Language. 2013; 27(6):1143-6. http:// dx.doi.org/10.1016/j.csl.2013.04.005.

Ming D, Zhu Y, Qi H, Wan B, Hu Y, Luk KDK. Study on EEG-based mouse system by using brain-computer interface. In: VECIMS 2009: Proceedings of the IEEE International Conference on Virtual Environments, Human-Computer Interfaces, and Measurements Systems; 2009. 2009. p. 236-9.

Molina AJ, Rivera O, Gómez IM, Sánchez G. Evaluation of unambiguous virtual keyboards with character prediction. Amsterdam: IOS Press; 2009. p. 144-9. (Assistive Technology from Adapted Equipment to Inclusive Environments, v. 25). http://dx.doi.org/10.3233/978-1-60750-042-1-144.

Naves E, Rocha L, Pino P. Alternative communication system for people with severe motor disabilities using myoelectric signal control. In: BRC 2012: Proceedings of the ISSNIP Biosignals and Biorobotics Conference: Biosignals and Robotics for Better and Safer Living; 2012. 2012.

Okasaka S, Hoshino Y. Development of estimation method about activity states for NIRS-based BCI system. In: Proceedings of the Soft Computing and Intelligent Systems (SCIS) and 13th International Symposium on Advanced Intelligent Systems (ISIS). 2012. p. 1144-9.

Orhan U, Hild KE, Erdogmus D, Roark B, Oken B, FriedOken M. RSVP keyboard: an EEG based typing interface. In: Proceedings of the ICASSP, IEEE International Conference on Acoustics, Speech and Signal. 2012. p. 645-8.

Ortner R, Allison BZ, Korisek G, Gaggl H, Pfurtscheller G. An SSVEP BCI to control a hand orthosis for persons with tetraplegia. IEEE Transactions on Neural Systems and Rehabilitation Engineering. 2011; 19(1):1-5. http://dx.doi. org/10.1109/TNSRE.2010.2076364. PMid:20875978.

Park S-W, Yim YL, Yi SH, Kim HY, Jung SM. Augmentative and alternative communication training using eye blink switch for locked-in syndrome patient. Annals of Rehabilitation Medicine. 2012; 36(2):268-72. http://dx.doi.org/10.5535/ arm.2012.36.2.268. PMid:22639753.

Pinheiro CG Jr, Naves ELM, Pino P, Losson E, Andrade AO, Bourhis G. Alternative communication systems for people with severe motor disabilities: a survey. Biomedical Engineering Online. 2011; 10(1):31. http://dx.doi.org/10.1186/1475925X-10-31. PMid:21507236.
Poláček O, M'ikovec Z, Slav'ik P. Predictive scanning keyboard operated by hissing. In: Proceedings of the 2nd IASTED International Conference Assistive Technologies; 2012. p. 862-9.

Prabhu V, Prasad G. Designing a virtual keyboard with multimodal access for people with disabilities. In: Proceedings of the 2011 World Congress on Information and Communication Technologies. 2011. p. 1133-8.

San Agustin J, Skovsgaard H, Mollenbach E, Barret M, Tall M, Hansen DW, Hansen, JP. Evaluation of a low-cost opensource gaze tracker. In: Proceedings of the 2010 Symposium on Eye-Tracking Research \& Applications. 2010. p. 77-80.

Schalk G, Brunner P, Gerhardt LA, Bischof H, Wolpaw JR. Brain-computer interfaces (BCIs): detection instead of classification. Journal of Neuroscience Methods. 2008; 167(1):51-62. http://dx.doi.org/10.1016/j.jneumeth.2007.08.010. PMid:17920134.

Silva F, Pereira F. Communication between people with motion and speech disabilities. In: Proceedings of the 6th Iberian Conference on Information Systems and Technologies. 2011. p. 1-4.

Simpson R. Making better decisions. IEEE Engineering in Medicine and Biology Magazine. 2008; 27(2):23-8. http:// dx.doi.org/10.1109/EMB.2007.907394. PMid:18463018.

Sörensen K. Multi-objective optimization of mobile phone keymaps for typing messages using a word list. European Journal of Operational Research. 2007; 179(3):838-46. http://dx.doi.org/10.1016/j.ejor.2005.03.069.

Sorger B, Dahmen B, Reithler J, Gosseries O, Maudoux A, Laureys S, Goebel R. Another kind of 'BOLD Response': answering multiple-choice questions via online decoded single-trial brain signals. Progress in Brain Research. 2009; 177:275-92. http://dx.doi.org/10.1016/S0079-6123(09)177191. PMid:19818908.

Sorna C, Steele R, Inoue A. Word prediction in assistive technologies for aphasia rehabilitation using systemic functional grammar. In: Proceedings of the Annual Conference of the North American Fuzzy Information Processing Society. 2009.

Sun GSG, Hu JHJ, Wu GWG. A novel frequency band selection method for common spatial pattern in motor imagery based brain computer interface. In: Proceedings of the 2010 International Joint Conference on Neural Networks; 18-23 July 2010; Barcelona. Barcelona: IEEE; 2010. p. 1-6. http:// dx.doi.org/10.1109/IJCNN.2010.5596474.

Thomas KP, Guan C, Tong LC, Prasad VA. An adaptive filter bank for motor imagery based Brain Computer Interface. IEEE Engineering in Medicine and Biology Society Annual Conference; 2008: 1104-7. http://dx.doi.org/10.1109/ IEMBS.2008.4649353. PMID: 19162856.

Thompson DE, Blain-Moraes S, Huggins JE. Performance assessment in brain-computer interface-based augmentative and alternative communication. Biomedical Engineering Online. 2013; 12:43. http://dx.doi.org/10.1186/1475925X-12-43. PMid:23680020.

Tsai MJ. Adults' preferences between Picture Communication Symbols (PCSs) and Gus Communication Symbols (GCSs) used in AAC. Research in Developmental Disabilities. 2013; 
34(10):3536-44. http://dx.doi.org/10.1016/j.ridd.2013.07.013 . PMid:23962601.

Usakli AB, Gurkan S, Aloise F, Vecchiato G, Babiloni F. A hybrid platform based on EOG and EEG signals to restore communication for patients afflicted with progressive motor neuron diseases. In: Proceedings of the 31st Annual International Conference of the IEEE Engineering in Medicine and Biology Society: Engineering the Future of Biomedicine. 2009. p. 543-6.
Wilkinson KM, Hennig S. The state of research and practice in augmentative and alternative communication for children with developmental/intellectual disabilities. Mental Retardation and Developmental Disabilities Research Reviews. 2007; 13(1):58-69. http://dx.doi.org/10.1002/ mrdd.20133. PMid:17326111.

Yin P-Y, Su E-P. Cyber Swarm optimization for general keyboard arrangement problem. International Journal of Industrial Ergonomics. 2011; 41(1):43-52. http://dx.doi. org/10.1016/j.ergon.2010.11.007.

\footnotetext{
Authors

Luiz Fernando Batista Loja ${ }^{1 *}$, Renato de Sousa Gomide ${ }^{1}$, Fabiana Freitas Mendes ${ }^{2}$, Ricardo Antonio Gonçalves Teixeira ${ }^{3}$, Rodrigo Pinto Lemos ${ }^{3}$, Edna Lúcia Flôres ${ }^{1}$

${ }^{1}$ Universidade Federal de Uberlândia - UFU, Rua João Naves de Avila, 2121, Santa Mônica, CEP 38408-100, Uberlândia, MG, Brazil.

${ }^{2}$ Universidade de Brasília - UnB, Campus Universitário Darcy Ribeiro, CEP 70910-900, Brasília, DF, Brazil.

${ }^{3}$ Universidade Federal de Goiás - UFG, Avenida Esperança, s/n, Setor Itatiaia, CEP 74690-900, Goiânia, GO, Brazil.
} 